\title{
A crítica do método marxiano à racionalidade burguesa e à educação tecnicista
}

\section{Criticism of the Marxian method against bourgeois rationality and technical education}

\section{Críticas del método marxista a la racionalidad burguesa y a la educación tecnicista}

\author{
Pereira, Francisco Vitor Macêdo ${ }^{1}$ (Redenção, CE, Brasil) \\ ORCID ID: 0000-0003-0474-7331 \\ Moraes, André Monteiro² (Campina Grande, PB, Brasil) \\ ORCID ID: https://orcid.org/0000-0003-3425-0457
}

\begin{abstract}
Resumo
Exercendo a interpretação materialista do desenvolvimento histórico e a visão dialética acerca das transformações sociais, o método marxiano segue sendo a mais adequada ferramenta teórica para a compreensão crítica das contradições da realidade social burguesa, ainda que visto por muitos de forma marginalizada e/ou ultrapassada. Marx vincula-se, na verdade, a um projeto revolucionário de sociedade e, em atenção à complexidade histórica desse projeto, a crítica à produção do conhecimento técnico e científico, assim como à educação como projeto enviesado de transformação social, requer um tratamento delicado: de análise acerca das bases de produção social das atuais instituições e modos da vida capitalista. Propomo-nos, diante disso, à explicitação de evidências a propósito da asserção e da atualidade desse método: como o que melhor possibilita a compreensão das contradições da realidade social burguesa, em face à explicitação de seus comprometimentos ideológicos na produção do conhecimento técnico-científico e na vituperação da educação das classes trabalhadoras.
\end{abstract}

Palavras-chave: Método marxiano. Crítica à racionalidade burguesa. Crítica à educação tecnicista.

\begin{abstract}
Exercising the materialist interpretation of historical development and the dialectical view of social transformations, the Marxian method remains the most adequate theoretical tool for the critical understanding of the contradictions of bourgeois social reality, although seen by many in a marginalized and / or outdated way. Marx is linked, in fact, to a revolutionary project of society and, in view of the historical complexity of this project, the criticism of the production of technical and scientific knowledge, as well as education as a biased project for social transformation, requires a delicate treatment: of analysis about the bases of social production of the current institutions and capitalist ways of life. Therefore, we propose to explain the evidence regarding the assertion and the relevance of this method: as the one that best enables the understanding of the contradictions of bourgeois social reality, in view of the explanation of their ideological commitments in the production of technical-scientific knowledge and in the vituperation of the working classes' education.
\end{abstract}

Keywords: Marxian method. Criticism of bourgeois rationality. Criticism of technical education.

\section{Resumen}

Ejerciendo la interpretación materialista del desarrollo histórico y la visión dialéctica de las transformaciones sociales, el método marxista sigue siendo la herramienta teórica más adecuada para la comprensión crítica

${ }^{1}$ Professor efetivo da Universidade da Integração Internacional da Lusofonia Afro-Brasileira/UNILAB. vitor@unilab.edu.br 2 Mestrando em Serviço Social pelo Programa de Pós-Graduação em Serviço Social da Universidade Estadual da Paraíba/ UEPB. andre.monteiro063@gmail.com 
de las contradicciones de la realidad social burguesa, aunque muchos la vean de manera marginada y / $u$ obsoleta. Marx está vinculado, de hecho, a un proyecto revolucionario de la sociedad y, en vista de la complejidad histórica de este proyecto, la crítica a la producción del conocimiento técnico y científico, así como a la educación como un proyecto sesgado para la transformación social, requiere un tratamiento delicado: de análisis sobre las bases de producción social de las actuales instituciones y formas de vida del capitalismo. Por lo tanto, proponemos explicar la evidenciación respecto a la afirmación y a la relevancia de este método: como el que mejor permite la comprensión de las contradicciones de la realidad social burguesa, en vista de la explicación de sus compromisos ideológicos con la producción del conocimiento técnico-científico y con la vituperación de la educación de las clases trabajadoras.

Palavras-Clave: Método marxista. Crítica a la racionalidad burguesa. Crítica a la educación tecnicista.

Todo começo é difícil em qualquer ciência.

(Karl Marx)

\section{Introdução}

Ante os conflitos históricos e as disputas de classe pelas riquezas e os meios de produção, o método de análise socioeconômica apresenta-se, em Karl Marx (18181883), como o melhor instrumento conceitual para desvendar criticamente as incoerências do modo de produção capitalista, nas atualíssimas engrenagens de desigualdade e exploração social da vida. Do que se segue a essa constatação, pretende-se para este artigo um percurso de revisão teórica, disposto a identificar no método de análise socioeconômica em Marx também uma ferramenta epistemológica: capaz de desvendar as bases ideológicas da exclusão e do elitismo, nas práticas burguesas de produção do conhecimento técnico e científico e de suas políticas educacionais.

Assumimos nesse percurso a discussão acerca da decadência da racionalidade moderna e do tecnicismo burguês, além das suas implicações nas atuais formas excludentes de produção do conhecimento científico. Expomos, em seguida, as nossas justificativas pela escolha desse método histórico-dialético como ferramenta de crítica da organização social burguesa, reforçando o entendimento de que a consciência histórica a respeito do materialismo apresenta-se, para as classes trabalhadoras, como condição emancipatória imprescindível à superação das estruturais desigualdades do capitalismo, rumo à edificação de outras sociabilidades possíveis. Por fim, questionamos os modelos de educação vigentes como resultado desse processo de decadência ideológica, de enviesamento técnico-racional e de mercantilização do conhecimento: enquanto projeto 
Revista Labor

Programa de Pós-graduação em Educação, Universidade Federal do Ceará

Fortaleza-CE-Brasil

alsor

de desestabilização da consciência da classe trabalhadora acerca de seu potencial emancipatório contra os ditames e interesses do capital.

A concepção deste trabalho se dá em uma dimensão interdisciplinar, no âmbito das ciências humanas e dos estudos sociais, abrindo por meio da discussão filosófica sobre a educação e o conhecimento um esteio para a crítica da produção social capitalista, de suas instituições e de suas formas de referenciar o conhecimento. Pautados na perspectiva do materialismo dialético, dispomo-nos ao exercício teórico e dinâmico de sucessivas aproximações da realidade, de forma crítica e propositiva à construção de práticas epistemológicas e educacionais condizentes com os interesses históricos das classes trabalhadoras.

\section{O método em Marx, o trabalho e o conhecimento: um percurso preciso}

O amadurecimento da sociabilidade burguesa, notadamente nos séculos XVIII e XIX, e as promessas e avanços do conhecimento científico possibilitaram a MarX a compreensão das desigualdades fundamentais do capitalismo, estruturadas, além da exploração do trabalho, igualmente nas distorções ideológicas da razão e da teoria do conhecimento: as quais até ali contribuíram, sem quaisquer críticas consistentes, para a reprodução das formas ideais de classe e dominação. Ao diagnosticar as bases socioeconômicas da inversão ideológica de prioridades no real, Karl Marx instaura um novo método de pensamento e crítica social.

O pensador que, segundo Engels (1993), foi o homem mais odiado e caluniado pela burguesia não ofereceu, todavia, um conjunto de novas e precisas regras para se empreender pesquisas sociais, tampouco disponibilizou definições ou conceitos propostos à inauguração de novas investigações sociais. Simplesmente, mediante a crítica fundamentada à reprodução ideal do movimento capitalista, ele efetiva a lógica materialista de suas análises socioeconômicas, e desmascara as bases estruturais da exploração burguesa sobre as classes trabalhadoras. Portanto, diferentemente dos pensadores modernos, Marx não funda as suas análises em postulados ou especulações gnosiológicas, mas em bases a uma ontologia de seu próprio tempo presente: a propósito 
Revista Labor

Programa de Pós-graduação em Educação, Universidade Federal do Ceará

Fortaleza-CE-Brasil

alsor

do diagnóstico das condições materiais de vida e de produção da realidade social em que se via historicamente inserido ${ }^{3}$.

Como consequência disso, ele compreende que as questões relativas ao conhecimento só têm como ser devidamente entendidas e atuadas, em seus precisos e reais termos, mediante a compreensão acerca do ser situado histórica e socialmente acentuadas a sua materialidade, a sua consciência e a sua temporalidade. "Por isso mesmo, para Marx, não há um método que possa ser apreendido previamente ao ato do conhecimento" (TONET, 2013, p. 71). Nesse caso, ele igualmente assume como ponto de partida, para uma possível teoria materialista e dialética do conhecimento, a própria gênese do ser social, como elemento vivo e fundante da sociabilidade.

A ideologização da vida social, para Marx, subsome-se, por isso, na inconsciência das classes trabalhadoras: a propósito do sequestro da produção material do trabalho socialmente sobrepujado; que é, no entanto, o único capaz de oferecer, não só o seu objeto para o conhecimento a propósito das condições de vida dos indivíduos, como também o seu próprio sistema de consumo. Por meio da explicitação e da articulação de categorias como produção-consumo, distribuição-troca, capital-trabalho, etc. o método crítico de análise socioeconômica em Marx supera, pois, o método empirista da economia política (CHAGAS, 2012).

O método marxiano confere, na verdade, uma crítica à economia política clássica e à dialética hegeliana, e não nega que a realidade deva ser pensada, em sua totalidade, a partir do trabalho e das condições materiais de produção da própria vida. Não há, nesse sentido, como se compreender o real a partir de aparências ou abstrações envoltas ideologicamente em representações, sistemas, narrativas e/ou determinações ideais - das quais supostamente derivem as condições ou as causas inaugurais de produção da vida para além do trabalho. A investigação social tem de se acercar, assim,

\footnotetext{
${ }^{3}$ Como se sabe, gnosiologia é o estudo da problemática do conhecimento. Nesse caso, portanto, o conhecimento em si é o objeto a ser idealmente estudado, assim como presumivelmente poderia ser qualquer outro objeto, dado ou abstratamente conferido à razão. Desse modo, o próprio conhecimento (gnosis) tende a ser abordado, de um ponto de vista gnosiológico, em proposições abstratas, absolutas e atemporais. Por sua vez, a ontologia é o estudo do ser e do conhecimento de si/em si, isto é, a apreensão das determinações efetivas a respeito daquilo que existe e do que preside historicamente aquela existência como tal. A ontologia pode ter um caráter geral, quando se refere a todo e qualquer ser existente, ou um caráter particular, quando diz respeito à esfera determinada de um ser em específico, como, por exemplo, o ser natural ou o ser social, em demanda ao diagnóstico atual de suas condições de existência (TONET, 2013, p. 12).
} 
Revista Labor

Programa de Pós-graduação em Educação, Universidade Federal do Ceará

Fortaleza-CE-Brasil

alsor

da própria materialidade da vida humana: minuciosamente em seus precisos aspectos e mecanismos de organização do trabalho, dos meios e instrumentos de produção, da disposição e dispensação das riquezas; de modo a que se descubra a conexão entre todos os seus elementos e de que, em seu bojo, se descreva e se apresente o movimento de produção e manutenção da realidade (CHAGAS, 2012).

Segundo Netto (2010), o método marxiano exige, portanto, a consciência histórico-dialética e materialista do pesquisador: que, na sua relação com o objeto ou a realidade que busca atualmente conhecer, deve extrair as múltiplas determinações de forças, de ordem prática e material, as quais dispõem as condições de operação e produção da realidade. Pelo diagnóstico dessas determinações de forças materiais que atualmente presidem a realidade, quanto mais se avança na pesquisa, mais se descobre historicamente as bases de estruturação do real e, consequentemente, mais se conhece ou se planeja praticamente as possibilidades de superação de suas desigualdades, deficiências e injustiças.

Percebemos, neste caso, na disposição do pesquisador à práxis, a indissociável conexão entre a formulação teórica e a postulação metodológica das ciências sociais em bases eminentemente materialistas. A unicidade entre teoria e prática é, com ênfase, uma característica imprescindível do método em Marx. É na prática que, de acordo com Marx e Engels (1993), o ser humano tende a mostrar a sua verdade histórica, conforme o comprometimento, as consequências e o poder de suas ações e pensamentos - voltados ao gerenciamento do trabalho e à utilização dos meios imprescindíveis à sua realização. Todavia, essa deve ser uma prática orientada por uma determinada teoria, de inteligibilidade histórica e finalidade ineludivelmente material: aferente à conscientização das classes trabalhadoras a propósito do controle técnico e econômico dos meios e das condições de produção da vida e da sociedade por intermédio do trabalho.

A perspectiva metodológica em Marx articula-se às categorias de i) totalidade (a sociedade burguesa é uma totalidade concreta, posto que distorcida e complexa: um complexo constituído por complexos), ii) contradição (os movimentos da sociedade burguesa resultam do seu caráter estruturalmente contraditório e, não por exceção, da administração de suas recorrentes crises) e iii) mediação (as relações na sociedade 
burguesa não são diretas, são mediadas pelos níveis de complexidade hierárquica e pela estrutural alienação da totalidade, ainda que esta última siga essencialmente forjada pelo trabalho) (NETTO, 2010, p. 18). Do que disso se segue, o método em Marx deve ser empregado de modo a que as investigações socioeconômicas e histórico-dialéticas primem por exaustivas pesquisas da realidade, estabelecendo categorias, relacionandoas, identificando as suas contradições e conexões práticas, descerrando a dinâmica dos meios pelos quais se organiza e se dispõe o trabalho à produção social. A lógica marxiana tem, portanto, na práxis o centro do processo de produção do conhecimento, afastando de suas análises todas as conceituações do empirismo mecanicista e do idealismo absoluto, recessivas ainda às teorias do conhecimento moderno. Essa lógica concebe diretamente a concretude das práticas sociais, tendo como base de sua operação o próprio processo do trabalho, que é o que de fato constrói e transforma a realidade (LUKÁCS, 2012).

Não se deve, por conseguinte, olvidar que, para Marx (2008), a existência e a reprodução social - e, portanto, da própria humanidade - se dá pela transformação cultural da natureza por meio da ação laboral. Diferentemente do que se passa com os demais seres do mundo natural, a relação ser humano-natureza é operada de forma consciente e planejada (LESSA \& TONET, 2008). O trabalho é, com efeito, a atividade fundante do ser social e de toda a sociabilidade, por permitir o total desenvolvimento das mediações e construções humanas; ou seja, de todas as suas mais diversas capacidades e habilidades essenciais - tais como a consciência, o conhecimento, a técnica, a totalidade, a cultura e a liberdade. Segundo Pontes (2000, p. 38), "o trabalho assume o papel condicionante da existência humana, porque proporciona necessariamente a sua socialização".

A maturação das discussões a respeito das mediações produzidas e diversificadas socialmente pelo trabalho segue supinamente conduzida, na tradição crítica marxista, por György Lukács (2012), que afirma que: "o trabalho dá lugar a uma dupla transformação. O próprio ser humano que trabalha é transformado por seu trabalho, ele atua sobre a natureza exterior e modifica, ao mesmo tempo, a sua própria natureza, desenvolvendo as potências que nela se encontram latentes" (LUKÁCS, 2012, p. 286). Do que disso se infere, é o próprio trabalho que apregoa ao ser humano a possibilidade e a 
Revista Labor

Programa de Pós-graduação em Educação, Universidade Federal do Ceará

Fortaleza-CE-Brasil

alsor

compreensão de sua totalidade: a propósito da realidade que lhe determina social e potencialmente a própria vida e a dos demais. De fato, "a realidade social se configura como um conjunto de partes, articuladas, em processo permanente de constituição, em determinação recíproca, e que, além disso, tem o trabalho como sua matriz fundante" (TONET, 2009, p. 08).

Nesse sentido, a integralidade do ato do trabalho, desde o seu momento mais original, se dá mediante "muitos outros elementos de consciência social junto à realidade (...), como a própria sociabilidade, a linguagem, a educação, o conhecimento" (TONET, 2009, p. 08), e, embora o ser humano formule objetivos, metas no campo de sua consciência, suas ideias só podem ser atuadas historicamente, somente assumem vida e expressão econômica, a partir da condição do que existe para a construção da realidade: injungida, portanto, ao que no mundo material a ação humana tornar-se capaz de entender e efetuar com proveito através do trabalho. Como consequência disso, compreende-se que o trabalho só transforma em humanidade aquilo que materialmente já existe e que tudo o que é material só é percebido como tal na condição em que se atualize como matéria para o trabalho.

(...) na produção social da própria existência, os homens entram em relações determinadas, necessárias, independentes de sua vontade; essas relações de produção correspondem a um grau determinado de desenvolvimento de suas forças produtivas materiais. A totalidade dessas relações de produção constitui a estrutura econômica da sociedade, a base real sobre a qual se eleva uma superestrutura jurídica e política e à qual correspondem formas sociais determinadas de consciência. $O$ modo de produção da vida material condiciona 0 processo de vida social, política e intelectual. Não é a consciência dos homens que determina o seu ser; ao contrário, é o seu ser social que determina sua consciência (MARX, 2008, p. 47).

Em síntese, na perspectiva marxiana, o ser humano tem invariavelmente como ponto de partida e como atual determinação histórica de sua humanidade a organização do trabalho; o qual, por sua vez, traduz-se na mediação indispensável para a transformação da natureza em estrutura social, econômica, política e jurídica - conforme a realização da consciência e do desenvolvimento técnico a propósito de suas forças produtivas. Mediando a si e à sua realidade pelo trabalho, o ser humano adequa a natureza 
Revista Labor

Programa de Pós-graduação em Educação, Universidade Federal do Ceará

Fortaleza-CE-Brasil

alsor

aos seus humanos fins: modificando-se a si mesmo, condicionando os seus processos de vida social, política e intelectual ao desenvolvimento laboral.

A partir do trabalho, portanto, uma série de complexidades se abre em margem às mais diversas dimensões e atividades vitais; sendo possível constatar, na propriedade, nos meios e técnicas da produção laboral, o que o ser humano de fato é: em síntese das forças as quais atual e decisivamente lhe determinam a historicidade, a materialidade e a sociabilidade da existência (TONET, 2013). Dessa premissa, entende-se que o trabalho é a categoria fundante e totalizante do ser social, de todos os seus complexos, potencialidades, disputas, conflitos e realizações; explicando igualmente 0 desenvolvimento das formas, graus e representações distintas da racionalidade e do conhecimento ao longo da história. À vista disso, uma vez que os processos laborais, dirigidos pelas necessidades de satisfação material e espiritual da humanidade, fazem emergir os conhecimentos teóricos, técnicos e científicos, esses mesmos conhecimentos refletem, em seus diferentes campos e classificações, as condições objetivas de produção histórica e material da sociedade (FORTI; GUERRA, 2009).

A despeito disso, a grande dificuldade em se abordar o conhecimento de forma crítica refunde, à cata de postulados, métodos e técnicas da atuação científica, nas disputas envoltas aos desvios epistemológicos e aos investimentos ideológicos, imantados pelos valores e interesses burgueses na sujeição das classes trabalhadoras. Os resultados da técnica e da ciência continuam, com efeito, até os dias de hoje, rotundamente acumulados por representações racionalistas modernas e elitistas. Sejam elas de ordem ideal ou empírica, as suas ambivalências seguem estruturando, de maneira sequaz, as diferenças essenciais de classe, raça e gênero: indispensáveis à manutenção da ordem e das técnicas de dominação, alienação e exploração do real pelo capital. Dessa forma, sob os influxos do capitalismo, da alienação do trabalho, do fetiche da mercadoria e das ideologias burguesas de diferenças essenciais, a racionalidade moderna ainda avança, sustentando a sua pretensão histórica: de enfeixar-se como único caminho, universal e necessário, para a análise e o esclarecimento a respeito de todas as problemáticas do conhecimento. 
Revista Labor

Programa de Pós-graduação em Educação, Universidade Federal do Ceará

Fortaleza-CE-Brasil

alsor

É importante, todavia, atentarmos para o fato de que a autenticação do conhecimento jamais se resumiu ao ensaio abstrato ou à capitalização especulativa das relações entre um sujeito hipotético e geral e um objeto provável. Estes, por sua feita, não atendem - nos simulacros de suas representações e formulações ideais - senão aos planos e exigências de forças: as quais, no mais das vezes, sucedem-se inteiramente alheias às determinações ontológicas da vida e de sua materialidade. Conquanto atuais e dispostas estruturalmente na organização do trabalho, essas forças agenciam, de modo histórico, não precisamente um regime geral e necessário, de anúncio e de produção da realidade, mas antes a convergência ideológica aos interesses de classe daqueles que controlam, de forma exploratória e desumanizante, os meios e as condições sociais de quem, efetivamente por meio do trabalho vivo, transforma e produz a inteira realidade.

Quando este sujeito moderno do conhecimento, que responde inominada e impessoalmente pelos atributos da razão, apresenta-se de forma ideal no polo regente do processo produtivo, a abordagem ou a dimensão cognitiva a respeito da realidade esfumase em abstrações de ordem gnosiológica; do contrário, sendo indicativa da própria ação do sujeito, imanente à existência material do objeto sobre o qual pretende atuar, a perspectiva do conhecimento materializa-se de maneira própria, como ser histórico e ação ontológica inteiramente conscientes de sua existência no mundo. Uma ou outra relação tem pesos totalmente diversos; haja vista que, se a abordagem cognitiva de qualquer objeto atender às formatações desse sujeito moderno e universal, preponderará, na produção de seu conhecimento, a propósito da razão e do tecnicismo burgueses, um viés absolutamente gnosiológico. Sendo, ao contrário, prática e ordenada ao mundo da vida, ela será ontológica. "A captura do próprio objeto implica o pressuposto de que ele não se resume aos seus elementos empíricos, mas também, e principalmente, àqueles que constituem a sua empregabilidade e interesse no mundo da prática" (TONET, 2013, p. 14).

Dessa forma, todo e qualquer processo de conhecimento está para além do exame da razão ou da mera detenção aos seus aspectos empírico-sensitivos, tendo-se em conta que, antes, as suas determinações assentam-se inerentemente à própria realizabilidade dos interesses do ser-no-mundo. Consoante uma prática inteiramente histórica de construção e manutenção social, o que se estabelece como modo ou 
Revista Labor

Programa de Pós-graduação em Educação, Universidade Federal do Ceará

Fortaleza-CE-Brasil

possibilidade de conhecimento acerca do ser não advém, todavia, de uma instância transcendente; nem reflete, como contraente, qualquer condição apriorística ao seu entendimento; tampouco serve pura ou exatamente à categorização de seus sentidos e efeitos materiais na prática da vida social. Conhecer o ser pressupõe conhecer a sua essência como coisa trazida ou forjada mediante o trabalho, é ter como premissa "o conhecimento da realidade, o modo e a possibilidade de conhecer a realidade a partir de sua produção" (KOSIK, 1976, p. 35).

Com ênfase, a realidade não se apresenta espontaneamente ao ser humano em nenhuma imediatez incólume nem encapsulada na condição indene e absoluta de um dado empírico qualquer. Dialeticamente, deve haver a distinção entre a representação, o conceito e a dureza do objeto em si: frente à humanidade do trabalho que historicamente o significou. Estas duas dimensões, do pensamento e da prática a propósito do real, são precisamente as qualidades da práxis - haja vista que, mediante o trabalho, na produção de si e de sua humanidade, o ser humano age consentânea e comunitariamente sobre a natureza e a sociedade: conforme a síntese dos interesses e necessidades as quais o jungem às relações com todos os demais seres de seu convívio. Nesse movimento, há de se compreender a ontologia do ser social em perspectiva emancipada, autônoma e solidária, uma vez que a moderna e atual problemática do conhecimento cinge-se ainda à calceta de um mendaz equívoco; ou melhor, segue engendrada à sombra da traição funcional e solipsista do concerto ideológico do capital: a mercê da alienação do trabalho e da consciência, da fragmentação do potencial revolucionário das classes trabalhadoras e em continuidade à expropriação da própria vida.

Sob os efeitos soturnos da lógica de um egoísmo maduro e da alienação do trabalho, a sujeição cumulativa ao conhecimento moderno implica em inadvertidamente se atribuir a prioridade dos investimentos epistemológicos ao conhecer ao invés de ao ser - a quem de fato são devidos a vida humana, a consciência, o estar-no-mundo e as possibilidades de liberdade. Inobstante a isso, tudo o que, com efeito, e humanamente é, é - e somente o é - como resultado de inter-relações históricas e materiais: forjadas e emancipadas precisamente no labor entre conhecimento e prática social; haja vista que 
Revista Labor

Programa de Pós-graduação em Educação, Universidade Federal do Ceará

Fortaleza-CE-Brasil

alsor

conhecer não tem como ser uma referência alheia ao processo de transformação da realidade (KOSIK, 1976, p. 35).

Todo e qualquer conhecimento é produzido, por isso mesmo, em determinado tempo histórico e social, ontologicamente mediado por práticas e instituições de potencial diagnóstico: quanto à localização e à especificação das condições de vida e de existência do ser. Mesmo o caráter de objetividade, comumente atribuído - a título de exatidão e verificabilidade - ao conhecimento técnico-científico, deriva igualmente da situação social do ser. Posto que insertada como dado, aferição ou informação cumulativa a respeito da realidade, o que determina a objetividade do conhecimento não é o fenômeno fortuito de nenhuma força sem agente, mas a interação precisa de instrumentos e interesses acionados de forma intencional na malha em que materialmente se tramam as ações da consciência humana: a respeito de si e da tessitura de suas possibilidades no mundo.

No fuso de inversão da produção social pelo capital, a vertiginosa complexidade das tramas nessa malha de ações manieta o cabedal da consciência do ser à urdidura incoerente de diversos falsos pontos e conexões. Conforme a factícia cosedura a que se veja socialmente alinhado, ou ainda esgarçado o tecido de sua vitalidade, o nível de consciência ou de alienação, de humanização ou de desumanização do ser vai transindose no alijamento cognitivo e operacional, maior ou menor, entre pensamento e realidade. Entre o que de si teria a tecer no mundo e o automatismo que então lhe sujeita, o ser vêse perpassado ao remendo de sua autodeterminação, à roca de sua alienação e ao retalhamento de seu potencial revolucionário.

\section{A decadência da racionalidade burguesa e suas implicações na produção do conhecimento científico}

As desigualdades essenciais, a lógica das sequências acumulativas e a cadeia da exploração material do trabalho para a produção concentrada de riquezas fazem com que, no sistema capitalista, entendamos a postulação e a verificação do conhecimento internamente conforme a regras de justificação e manutenção da divisão social em classes. Historicizar o processo de produção do conhecimento no capitalismo é um meio para se compreender a instituição ou a naturalização dessa divisão social em classes - 
Revista Labor

Programa de Pós-graduação em Educação, Universidade Federal do Ceará

Fortaleza-CE-Brasil

com base na subserviência e exploração dos trabalhadores ${ }^{4}$. Com ênfase, a estruturação social da produção da vida em classes traduz, de maneira fundamental, a história da produção do conhecimento científico em termos elitistas, racistas e depredatórios da vida e da natureza.

O que há de comum em todos os processos históricos de produção do conhecimento, mesmo antes do racionalismo, do cientificismo moderno e da atualidade do capitalismo financeiro e tecnológico, é a condição de que o mesmo intermedeie todas as atividades inerentes à própria manutenção da vida humana, particularmente no que concerne ao desenvolvimento de práticas de compreensão, intervenção e transformação da natureza em realidade cultural, técnica e social. Atua-se a produção do conhecimento, pois, não apenas para a mera e inconsequente explicação dos fenômenos da natureza e da vida humana, mas a fim de que se materialize, se construa e se efetive a realidade de sua ordem cultural, simbólica e social.

A respeito da crítica marxiana às pretensões gnosiológicas de obtenção ideal e representação alienada do conhecimento, propõe-se o diagnóstico ontológico das condições materiais e atuais de produção da vida, bem como da conjunção das forças as quais presidem, elas mesmas, a construção do conhecimento. Conforme o arranjo histórico e localizado das disputas, valores e interesses imanentes à asserção dos modos e comportamentos vitais dos sujeitos, em suas relações e interações sociais mediante o trabalho, os mesmos forjam o seu conhecimento em estruturas de maior ou menor duração. Há, contudo, uma nítida divisão entre os conhecimentos práticos e aferentes ao trabalho manual e os conhecimentos teórico-científicos, laudatórios do trabalho intelectual, acumulativo e elitizado, e que estruturam ideologicamente as engrenagens da sociabilidade do capital. Essas disposições de classe e hierarquia, quanto aos tipos e a

\footnotetext{
${ }^{4}$ Como se sabe, classes sociais são grandes grupos ou segmentos de população que, no contexto do capitalismo, circunscrevem-se aos processos históricos de produção e expropriação de riquezas. Cada um desses grupos identificase por inúmeros e variados interesses, dos quais nem todos os membros têm consciência. Alguns desses interesses, do ponto de vista material, são básicos e, por isso, também inegavelmente comuns a todos os indivíduos que compõem cada um daqueles grupos. Dessa forma, ao longo da História mais recente do sistema de produção do capital, temos encontrado duas classes fundamentais: a daqueles que produzem a riqueza e a daqueles que são proprietários dos meios de produção, e que se apropriam da maior parte da riqueza produzida. Entre essas duas classes existem diversos segmentos, os quais não produzem, por meio do trabalho vivo, a riqueza material, mas que se apropriam de parte dela, sendo, contudo, do ponto de vista estrutural, menos importantes (TONET, 2013, p. 16).
} 
Revista Labor

Programa de Pós-graduação em Educação, Universidade Federal do Ceará

Fortaleza-CE-Brasil

produção do conhecimento, resultam em importantes consequências para as divergentes visões e concepções de mundo (TONET, 2013).

De fato, historicamente, a abordagem das questões relativas ao conhecimento se deu sob essas duas perspectivas (gnosiológica e ontológica). Menosprezando a compreensão histórica, a abordagem gnosiológica, que se apresenta como o verdadeiro e único caminho para a produção de conhecimento científico, desqualifica o tratamento ontológico da problemática do conhecimento (TONET, 2013, p. 15, grifos nossos).

A isso equivale dizer que, porquanto a busca pelo conhecimento assuma igualmente instrumentos ou formas de expressão como a arte, a poesia ou a religião, é a ciência que tem adquirido - na perspectiva gnosiológica, alienante a absolutizante do capital - o mito da superioridade e da precisão (MINAYO, 2012). Com aparente caráter de imutabilidade e naturalidade, a ciência vem conseguindo, desde a modernidade, influenciar a totalidade da busca e da produção cognitiva e epistemológica, deixando à margem os demais instrumentos e formas de expressão do saber.

Os séculos XVIII e XIX têm como grande marca as revoluções no campo das ciências da natureza e exatas, principalmente. Esse período demarca um processo histórico-social considerado muito relevante para a humanidade. Conhecido como o primado da razão, e caracterizado "por um movimento progressista, ascendente, orientado no sentido da elaboração de uma racionalidade humanista e dialética" (COUTINHO, 2010, p. 20), esse período histórico tem, em sua centralidade, o rompimento com a tradição secular, de entendimento acerca da natureza, do mundo e da humanidade por meio da religião. Segundo Tonet (2013), o surgimento do mundo moderno, no campo do conhecimento, destaca-se precisamente na transição da centralidade no objeto para o sujeito, e essa mudança de paradigma prevalece epistemologicamente até os dias de hoje.

O conhecimento é paulatinamente retirado das concepções dogmáticas acerca do mundo, a "razão moderna é suportada pela objetividade e processualidade as quais ela verifica e reconstrói na realidade" (NETTO, 1994, p. 28). Cabe destacar que essas mudanças assinaladas repercutirão não apenas "no campo epistemológico, mas também na economia, na política, na ética e na estética" (SIMIONATTO, 2009, p. 01). 


\begin{abstract}
Vale notar que, ao longo deste processo, também vão se constituindo as duas grandes classes que serão os eixos fundamentais desta nova sociedade: a classe burguesa e a classe proletária. A primeira, através da transformação de alguns servos e camponeses em comerciantes e depois em industriais e a segunda através da transformação da maioria dos servos em força de trabalho livre. Deste modo, vai se constituindo a célula mater da nova forma de sociabilidade: o ato de compra-e-venda de força de trabalho, com todas as suas exigências e consequências até o presente (TONET, 2013, p. 30).
\end{abstract}

A história da razão moderna, entretanto, não se constitui apenas em um movimento progressivo. Entende-se que, dadas às condições materiais, há uma primeira etapa progressista, conforme assinalado acima, que se inicia em meio aos pensadores renascentistas e que tem seu último e máximo expoente em Hegel, que é quem sintetiza e eleva as conquistas de todo esse período em três categorias fundamentais: i) historicismo - conforme o entendimento de que o ser humano é produto de sua história coletiva; ii) humanismo - que observa o caráter ontológico da realidade; e iii) razão dialética - perspectiva metodológica de entendimento do real como processualidade e unidade de contrários, além da possibilidade de apreensão subjetiva do conhecimento (COUTINHO, 2010).

Posteriormente, os avanços que denotam essa etapa progressista da filosofia idealista burguesa são substituídos pelo período de decadência ideológica, ou de miséria da razão, nos termos de Coutinho (2010). Cronologicamente, essa decadência tem início no segundo quartel do século XIX, quando o proletariado torna-se classe para si, colocando-se em defesa de interesses antagônicos aos da burguesia, delineando novos percursos à luta de classes e impondo o fim da suposta representatividade burguesa acerca dos interesses gerais, universais e necessários da humanidade.

O período da decadência caracteriza-se, hegemonicamente, pela limitação ou negação dos alcances da razão - em favor da eficácia instrumental e da prontidão dos resultados da técnica -, tanto quanto pelo abandono parcial dos paradigmas de grandes modelos e verdades científicos. Outras características podem ser assinaladas: quanto à i) acentuação das injustiças e desigualdades em proporção à insofismável divisão e precarização social do trabalho, refletindo-se também na ii) intensiva especialização das ciências e no freio à generalização dos conhecimentos, ademais de iii) relativizar e mesmo expurgar dos debates científicos algumas categorias outrora consideradas centrais para o 
Revista Labor

Programa de Pós-graduação em Educação, Universidade Federal do Ceará

Fortaleza-CE-Brasil

entendimento da humanidade, tais como a ética e a ontologia - as quais passam, cada vez mais, a exercer apenas controles e/ou censos de caráter eminentemente normativo e procedimental; quando não tidas, por alguns utilitaristas e pragmatistas, como apêndices insensatos ou mesmo filigranas convencionais, a reduzirem-se atualmente a meros artigos da ideologia e do moralismo burgueses.

Aliás, este é um traço comum da decadência filosófica burguesa: muito do que se arroga à cientificidade não passa de procuração ideológica, em atualização aos expedientes de supressão e opressão da realidade pelo capital. Sob os efeitos de ideologização das ciências, notadamente na perspectiva do conformismo e da resignação, repaginam-se o individualismo, o historicismo subjetivista e o irracionalismo (COUTINHO, 2010). Em reedição dos resultados dessa decadência, alhures ao racismo, à eugenia e ao elitismo - como marcas as quais ainda recidivam da racionalidade burguesa moderna -, ora temos a exacerbação última de relativismos e pós-verdades: em meio ao espectro atual de expressões fascistas e ultraliberais do pensamento pós-moderno. Essas novas configurações serão detalhadas no item seguinte, com particularidade quanto às implicações educacionais.

\subsection{As expressões da decadência ideológica burguesa no processo (des)educativo das classes trabalhadoras}

Consoantes à mimetização superestrutural do (neo)liberalismo em apanágios de flexibilidade jurídica e à mesmerização das consciências face à virtuose das tecnologias, os atuais processos ideológicos da hegemonia burguesa prosseguem firmes e habilíssimos na expansão da reificação e da alienação das classes trabalhadoras (COUTINHO, 2006). Na esfera propriamente econômica, dissemina-se crescentemente o emblema do empreendedorismo, para a socialização de supostos novos valores e regras de iniciativa e comportamento, além do protocolo de pactos de consenso e transigência de direitos diretamente entre trabalhadores e capitalistas. A cultura política antiestatista acelera a privatização total de bens, riquezas e serviços, tornando-se corolário incontrastável da supremacia monetária do lucro e do mercado financeiro de capitais. Nessa mesma medida, amplia-se a descrença na gestão pública, e as tendências maduras 
Revista Labor

Programa de Pós-graduação em Educação, Universidade Federal do Ceará

Fortaleza-CE-Brasil

alsor

do egoísmo e da responsabilização mínima fazem com que a visão de menoscabo da realidade social converta-se em passividade e conformismo por parte das classes trabalhadoras (SIMIONATTO, 2009).

A consecução do projeto capitalista, em sua atual fase de globalização financeira e corporativismo tecnológico, sobrepuja igualmente a educação aos efeitos da instrumentalização técnica e da mitigação da humanidade à condição de insumo econômico ${ }^{5}$ (FRIGOTTO, 1984). Nesse caso, a vinculação necessária entre educação, qualificação para o trabalho e processo produtivo se dá, ainda no âmbito do século $X X$, segundo Frigotto (1984), como um dos mais básicos mecanismos de inversão ontológica da realidade. Até então sob a tutela das políticas estatais, ante o recrudescimento das crises produtivas do capitalismo em sua fase monopolista, o alvo dos interesses para a educação voltava-se, no bojo de estratégias de currículos e habilidades, à disposição de mão-de-obra para a imediata produção de riquezas e a realização de mais-valia.

Sendo assim, todo o aparato escolar e pedagógico, fornecido ou mediado pelo estado como superestrutura do capital - atendendo, portanto, à mercantilização ou capitalização da própria humanidade como insumo ou recurso econômico -, liga-se, principalmente a partir da década de 1950, a uma perspectiva acentuadamente tecnicista: com o intuito de equipar a formação e a qualificação das classes trabalhadoras com metodologias e tecnologias adequadas à constituição da educação como um investimento - capaz de gerar um novo tipo de capital humano. Nas décadas de 1960 e 1970, esse investimento educacional, admitido como qualificação ou reserva técnica de mão-de-obra, seguiu sendo amplamente intensificado: a fim de supostamente resolver os problemas do subdesenvolvimento e das desigualdades nas esferas internacional, nacional, regional e individual. Nesse contexto, entretanto, "a educação é reduzida a um mero fator de produção" (FRIGOTTO, 1984, p. 121).

\footnotetext{
${ }^{5} \mathrm{~A}$ teoria do capital humano representa a forma pela qual a visão burguesa reduz a prática educacional a um fator de produção, a uma questão eminentemente técnica. A educação, o treinamento, que aparecem como fatores determinantes do desenvolvimento econômico, da equalização social, são, na verdade, determinados pelo interesse primitivo da acumulação capitalista, ainda quando as pesquisas sociais discutam as variáveis do acesso e do sucesso escolar em termos de direitos e políticas públicas. A relevância dos vínculos que se busca estabelecer entre educação e desenvolvimento, educação e trabalho tem de ser compreendida não pela perspectiva técnica, nem mesmo política, mas conforme o sentido ou o intuito de se desmascarar a natureza desses vínculos no interior das próprias relações sociais de produção da sociedade capitalista (FRIGOTTO, 1984, p. 18-19).
} 
Revista Labor

Programa de Pós-graduação em Educação, Universidade Federal do Ceará

Fortaleza-CE-Brasil

alsor

Atualmente, adrede às investidas da automação, da informatização e da robotização produtivas, avulta-se a descartabilidade de cada vez mais trabalhadoras/es, nos mais diversos setores de serviços e categorias laborais. De fato, o capital já parece operar em uma era de pós-direitos, na qual se extinguem praticamente todas as premissas e garantias sociais e trabalhistas, assumindo-se abertamente a precarização sem par das condições de trabalho e o abandono sistemático dos/as trabalhadores/as à informalidade e ao subemprego. A minimização da educação ao treino escolar e à qualificação técnica serviu, nesse cenário, para o capital atingir produção invariavelmente imediata e sempre renovada, de acordo com a formação exponencial de cadastros de seres humanos como vulgar reserva técnica.

Notadamente a partir da década de 1980, a introdução de novas tecnologias e de novas formas de organização dos processos produtivos, a título de flexibilização e liberalismo econômico, articulada à relativização de direitos sociais e trabalhistas e à globalização das relações de produção, tem cumprido a agenda do desmonte total das garantias e direitos sociais das classes trabalhadoras. As reformas infligidas por essa agenda econômica do (neo)liberalismo global exigiram, desde então, a formação profissional preparada para lidar com a fluidez das inovações técnico-organizacionais, em consonância à mentalidade de empreendedorismo, individualismo e competição, associada à crescente precarização das condições de trabalho (ANDRADE, 2000).

O estado intensificaria, a partir daí, a lógica (neo)liberal e corporativa também em suas políticas educacionais, com reforço na suposta proposição democrática de inclusão das massas, atrelada à necessidade de, em tese, melhorar a qualidade do ensino em função da geração de emprego e renda. Essa temática da qualidade do ensino tem, com efeito, assumido diversos aspectos e significados, todos relacionando a educação à condição de insumo da produção capitalista. Na associação invariável a esse escopo, atribui-se, muitas vezes, à simples escolarização ou formação técnica o papel feérico do resgate de estruturais dívidas históricas e sociais; o que, todavia, reforça a educação como estreme frente de serviço e atendimento à reprodução ampliada do capital (NEVES, 2000).

Subordinando a mendaz melhoria da qualidade de vida às necessidades de acumulação do capital, o empresariado financeiro e industrial brasileiro, na fase inicial dos 
anos 1990, expressou a sua preocupação quanto à necessidade de elevação do nível educacional e do patamar científico e tecnológico no país; apresentando então ao governo e à sociedade a necessidade funcional de renovados quadros e formação qualificada ao desenvolvimento nacional, assim como de novas políticas de profissionalização das classes trabalhadoras (NEVES, 2000).

A burguesia industrial e financeira - através de suas instâncias representativas/organizativas - vai procurar construir, tendo em vista a efetivação daquele movimento de mudança cultural, um projeto ideológico-político de conformação da sociedade às novas demandas postas pelas transformações do sistema produtivo, objetivando, em última instância, a formação da força de trabalho correspondente a tais transformações (ALMEIDA, 2000, p. 66).

Há, neste caso, a flagrante necessidade do capital em deter o processo educativo entrelaçado aos valores e habilidades exigíveis - em meio a estes repaginados cenários financeiros e tecnológicos. Como consequência disso, a preocupação quanto à adequação da base humana às exigências desse gerenciamento, em escala crescentemente global, não se volta precisamente ao destaque dos interesses e necessidades dos indivíduos, em um liberal e competitivo mercado de oportunidades de trabalho, mas à formação das futuras gerações como reservas técnicas e continuamente atualizadas de mão-de-obra à disposição do capital. Segundo Almeida (2000, p. 70), a instância educacional se vê, pois, sob esse contínuo influxo, sendo transformada para atualizar-se, simultânea e paradoxalmente, como alavanca e repositório de habilitação dos sujeitos: em relações cada vez mais fluidas e arrogadas a promessas falsas de liberdade e de construção de novos padrões de vida.

Como dissemos, essa imantação do (neo)liberalismo sobre os processos educacionais torna-se irresistivelmente ainda mais acentuada ante as características contemporâneas de minimização do estado e das políticas sociais. Na sucessão de crises e contradições, em que viceja a dinâmica do capital, observa-se, de forma cada vez mais intensa e em bases sempre mais voláteis, a desestruturação ou o desmonte de todas as políticas sociais - em substituição por políticas de desenvolvimento, de financiamento ou de fomento econômico. A consequência mais evidente disso é o aumento substancial das desigualdades sociais, dos níveis de endividamento e da pobreza em quase todo o mundo, 
Revista Labor

Programa de Pós-graduação em Educação, Universidade Federal do Ceará

Fortaleza-CE-Brasil

provocado vertiginosamente pelas políticas monetárias e neoliberais de um consórcio global e sem termos - entre estados, organismos internacionais e corporações financeiras (MOTA \& AMARAL, 1998).

A adesão sem travas dos governos brasileiros a esse ideário neoliberal tem exigido, além de exaustivos ajustes econômicos e fiscais, também o cerceamento da maioria dos direitos da população. Sob a justificativa de reformas essenciais para 0 desenvolvimento do país, com vistas à superação das seguidas crises econômicas, o pacote mínimo de cidadania tem sido deliberadamente entregue aos interesses do capital (MORAES, 2018). De acordo com essa cartilha neoliberal, também aos indivíduos Ihes é outorgada a perseguição de patamares de lucratividade, de liberdade de iniciativa e de reflexão mínima sobre as consequências sociais de seu alvedrio e de suas atitudes - em adição à irrefreável busca por sucesso e vantagens pessoais. Como incautas pantomimas empresariais, a maioria acredita incorporar os comportamentos de uma vida consumista, empreendedora e pequeno-burguesa. Identificados com os diferentes estratos da classe média, esses indivíduos relegam a sua formação educacional a mais um índice, de médio e longo prazo, utilitariamente aplicado como investimento econômico de suas vãs empresas vitais.

Não obstante a toda essa degradação da vida social, os argumentos sobre o neoliberalismo fundamentam sobejamente as ideologias do capital financeiro - reforçando, pois, o discurso pós-moderno de que as crises econômicas enfrentadas resultam prioritariamente dos gastos excessivos com políticas públicas (CHAVES, 2012). Com efeito, na tentativa de dar respostas satisfatórias à "sacralização do mercado" (LÖWY, 1999), na promessa da captação de investidores internacionais, os estados e demais entidades representativas têm atuado ostensivamente para a mercantilização da vida social e a (re)funcionalização da educação aos ditames e interesses (neo)liberais.

\section{Considerações Finais}

Não é incomum associarmos, até os dias de hoje, as discussões do método científico aos padrões de conhecimento da ciência moderna; sem, contudo, atentarmos para as suas reais bases de dominação quanto ao racismo, à colonialidade, ao elitismo e 
às demais desigualdades essenciais: presentemente ainda dadas em manutenção dos expedientes e dispositivos ideológicos de exploração da vida pelo capital. Não questionar as formas de se fazer e de se promover ciência faz com que, no entanto, sejamos guiados/as pelo falseamento da produção do conhecimento e da técnica, e isso necessariamente implica numa compreensão distorcida acerca da educação e das prioridades para a formação e o enfrentamento da realidade pelas classes trabalhadoras.

A compreensão histórico-dialética do método materialista nos permite, em Karl Marx (2008), por meio da crítica de sua análise socioeconômica, superar a abstração das abordagens de convenções cognitivas e epistemológicas, dispostas desde a modernidade em paradigmas de unicidade e irreversibilidade. Para as matrizes universalistas do conhecimento moderno, não há a possibilidade de novas concepções de mundo, tampouco formas alternativas de se produzir o conhecimento científico para além da humanidade burguesa e da racionalidade do capitalismo ocidental. A justa compreensão da problemática do conhecimento implica, no entanto, que este seja tratado no conjunto dos processos históricos e sociais do ser, conforme a dialética das transformações materiais em torno das disputas e conflitos pela produção de riquezas e manutenção da vida (TONET, 2013). Diante disso, o método crítico dialético, que historicamente dá conta de compreender as contradições socioeconômicas da sociabilidade burguesa, é o que melhor nos proporciona o conhecimento das bases e forças materiais de produção da realidade por intermédio do trabalho, precisamente na radicação de seu potencial emancipador e revolucionário à superação do capitalismo.

Esse método crítico em Marx (2008) é, portanto, indiscutivelmente atual e necessário à ultrapassagem das desigualdades e injustiças socioeconômicas em nossa sociedade - especificamente de capitalismo tardio e periférico (CHAGAS, 2012). Dado à fundamentação de outra sociabilidade possível, na busca pelo conhecimento necessário à conscientização do papel histórico de emancipação da humanidade pelas classes trabalhadoras, o método em Marx (2008) nos permite ter a visão total da dinâmica societária vigente, tornando-nos sensíveis à apropriação crítica de seus problemas, em resistência às imposturas da racionalidade e da técnica burguesas. 
Revista Labor

Programa de Pós-graduação em Educação, Universidade Federal do Ceará

Fortaleza-CE-Brasil

alsor

Fato é que, em suas atuais dimensões de alienação e de inversão da ordem da realidade, o capitalismo arroja-nos a uma civilização de consumo, descarte, egoísmo e indiferença. Contrariamente a essa horrenda dissipação ontológica, conferindo-nos os indicativos materiais à eficiente superação da acumulação primitiva e da lógica de exploração do humano pelo humano, o método marxiano manifesta-se como ferramenta essencial de crítica e resistência: na luta das/os trabalhadoras/es pela manutenção e dignidade da vida humana no planeta. Os aportes teóricos da crítica proporcionada por esse método ensejam-nos, ademais, novos e genuínos modos de investigação científica, além de perspectivas educacionais de real emancipação, sobre os desvanecimentos da técnica e da formação escolar.

Autenticada no que concerne à problematização, teorização e metodologia de estudos e pesquisas sociais - em comprometimento com os interesses da vida, da justiça e da diversidade, tanto quanto com o desenvolvimento humano e a preservação da natureza -, a práxis dialética seguirá impulsionando-nos: no embate histórico de forças e potências sobre nós mesmos, até a final superação de todas as incoerências da propriedade e da exploração em desfavor das classes trabalhadoras. À revelia dessa conscientização, as atuais políticas educacionais seguem, no entanto, segundo Senra (2000), em colusão com os interesses do grande capital, e também do conhecimento científico como um irrefletido insumo à obtenção do lucro.

Visando atender de modo cego apenas às demandas corporativas do capital financeiro e tecnológico, as edições estratégicas para a atual dominação do trabalho e da vida social acabam, na medida em que fornecem e instrumentam as técnicas de desumanização laboral, conferindo um sentido absolutamente deletério às suas formações e ações eclipsantes, sendo de fato infestadas pela lógica mesquinha e utilitária do desempenho e da competição profissional. Sob o influxo dos investimentos às insensatas qualificações e habilitações técnicas dos/as trabalhadores/as, as suas diretrizes estendidas ao sistema educacional, e ao processo de universalização da escolaridade, dão-se mediante a disparatada empresa de instabilidade funcional e reciclagem maquinal da força de trabalho. O conhecimento científico, por sua vez, é igualmente reduzido a um periférico mecanismo de capacitação profissional. 
Revista Labor

Programa de Pós-graduação em Educação, Universidade Federal do Ceará

Fortaleza-CE-Brasil

Conforme Frigotto (2010), a educação no Brasil segue sendo mitigada e desumanizada pelo economicismo e pelas reformas (neo)liberais, além de cada vez mais vista como um mero fator de disponibilização de mão-de-obra: alienada, inopinada e desarticulada à sua própria consciência de classe. A abstração e a ausência crítica dos atuais modelos ou propostas educacionais, ante a real estruturação das relações de poder e de exploração da vida pelo capital, reduzem os contingentes de trabalhadores/as à sua estrita avaliação como mercadoria - tecnicamente hábil, qualificada, servil, aprovada e competitiva à sobreposição das técnicas e métodos de treinamento. Afere-se a eficácia desse/a trabalhador/a na dispensação de seu labor como recurso humano: negociável em contínua fluidez, volatizada/o como valor de troca e versátil ao improviso ou precarização de qualquer adveniente condição de trabalho.

Em meio a todo esse ambiente neoliberal de empreendedorismo, escassez e competitividade, e a despeito de todo o fetiche que se promove também sobre a educação, ela mesma como um produto ou serviço capaz de fornecer àquele/a que se forma alguma ilusão de estabilidade ou de improvável status, o que a análise das condições materiais de produção da vida nos revela é a constatação do crescimento inconsiderado das desigualdades e das sucessivas crises, sempre mais incontornáveis, do capitalismo. É assim que a educação se torna, não apenas instrumento de controle ideológico, como passa, ela própria, por um processo de fetichização. Sendo assim, de forma equivocada, a educação, em seu atual escopo tecnicista e empreendedor, é então promovida, ou vendida ela mesma, como plataforma de fictícia ascensão e transformação social.

\section{Referências}

ALMEIDA, N. L. T. de. O serviço social na educação: novas perspectivas sócioocupacionais. Belo Horizonte, 2007. Disponível em: <http://necad.paginas.ufsc.br/files/2012/07/O_Servico_Social_na_Educacao_perspectiva s_socio_ocupacionais1.pdf> Acesso em: 21 ago. 2018.

ANDRADE, Flávio A. A formação do "cidadão-trabalhador": educação e cidadania no contexto do "novo industrialismo". In: NEVES, L. M. W. Educação e política no limiar do século XXI. Campinas, SP: Autores Associados, 2000. p. 59-78. 
Revista Labor

Programa de Pós-graduação em Educação, Universidade Federal do Ceará

Fortaleza-CE-Brasil

BEHRING, E. R. Brasil em contrarreforma: desestruturação do Estado e perda de direitos. São Paulo: Cortez, 2003.

BRANDÃO, S. M. O. A produção do conhecimento no contexto da pesquisa social: um ensaio exploratório. In: $V$ JORNADA INTERNACIONAL DE POLÍTICAS PÚBLICAS, 5. 2011, São Luís. Anais... São Luís - MA: UFMA, 2011. p. 1-13.

CHAGAS, Eduardo F. O método dialético de Marx: investigação e exposição crítica do objeto. Campinas, SP: Unicamp, 2012.

CHAVES, Vera L. J. Educação pública, gratuita e de qualidade na perspectiva do trabalho. In: BERTOLDO, E.; MOREIRA, L. A. L.; JIMENEZ, S. (Orgs.). Trabalho, educação e formação humana frente à necessidade histórica da revolução. São Paulo: Instituto Lukács, 2012. p. 201-214.

COUTINHO, C. N. O estruturalismo e a miséria da razão. 2 ed. São Paulo: Expressão Popular, 2010.

FORTI, V; GUERRA, Y. "Na prática a teoria é outra?". In: FORTI e GUERRA. (Orgs.). Serviço Social: Temas, Textos e Contextos, Rio de Janeiro, Lumen Juris, 2009. p. 03-22.

FRIGOTTO, Gaudêncio. A produtividade da escola improdutiva: um (re)exame das relações entre educação e estrutura econômico-social capitalista. São Paulo: Cortez, autores associados, 1984.

. Educação e a crise do capitalismo real. São Paulo: Cortez, 2010.

KOSIK, K. Dialética do concreto. Rio de Janeiro: Paz e Terra, 1976.

LESSA, Sérgio; TONET, Ivo. Introdução à filosofia de Marx. São Paulo: Expressão Popular, 2008.

LÖWY, Michel. Estado, democracia e alternativa socialista na era neoliberal. Diálogo coordenado por Pablo Gentili, Luis Fernandes e Emilio Taddei. In: SADER, Emir; GENTILI, Pablo (Orgs.). Pós-neoliberalismo II: que estado para que democracia? Petrópolis, RJ: Vozes, 1999. p. 77-92.

LUKÁCS, György. Para uma ontologia do ser social. São Paulo: Editora Boitempo, 2012.

MARX, Karl. Contribuição à crítica da economia política. 2. Ed. São Paulo: Expressão popular, 2008. 
; ENGELS, F. A ideologia alemã. São Paulo: Hucitec, 1993.

MINAYO, M. C. S. Pesquisa social: teoria, método e criatividade. Petrópolis, RJ: Vozes, 2012.

MORAES, A. M. O Serviço Social e a educação em contexto neoliberal: o trabalho do assistente social na Escola Municipal Gustavo Adolfo Cândido Alves - Campina Grande/PB. Monografia em Serviço Social. Universidade Estadual da Paraíba - UEPB. Campina Grande, PB, 2018.

MOTA, Ana E.; AMARAL, Ângela S. Reestruturação do capital, fragmentação do trabalho e Serviço Social. In: MOTA, A. E. (Org.). A nova fábrica de consensos. São Paulo: Cortez, 1998. p. 23-44.

NETTO, J. P. Razão, ontologia e práxis. Serviço Social \& Sociedade, v. 44, p. 26-42, ano 15, 1994.

Introdução ao método da teoria social. São Paulo: Expressão Popular, 2010.

NEVES, Lúcia M. W. Determinantes das mudanças no conteúdo das propostas educacionais no Brasil dos anos 90: período Itamar Franco. In: NEVES, L. M. W. Educação e política no limiar do século XXI. Campinas, SP: Autores Associados, 2000. p. 05-58.

Brasil 2000: nova visão de trabalho na educação. São Paulo: Xamã, 2000.

PONTES, Reinaldo Magalhães. Mediação: categoria fundamental para o trabalho do assistente social. In: Capacitação em Serviço Social e Política Social, Módulo 04: 0 trabalho do assistente social e as políticas sociais. Brasília: Cead, 2000.

SENRA, Alvaro de O. Propostas educacionais da Igreja Católica sob o neoliberalismo. In: NEVES, L. M. W. Educação e política no limiar do século XXI. Campinas, SP: Autores Associados, 2000. p. 133-146.

SIMIONATO, I. Serviço Social: direitos sociais e competências profissionais. In: As expressões ideoculturais da crise capitalista na atualidade e sua influência teóricopolítica. Brasília: CFESS/ABEPSS, 2009.

TONET, Ivo. Educação e ontologia marxiana. Maceió, 2009. Disponível em: $<$ http://ivotonet.xp3.biz/arquivos/EDUCACAO_E_ONTOLOGIA_MARXIANA.pdf> Acesso em: 20 set. 2019. 


\section{Revista Labor}

Programa de Pós-graduação em Educação, Universidade Federal do Ceará

Fortaleza-CE-Brasil

Método científico: uma abordagem ontológica. São Paulo: Instituto Lucaks, 2013.

\section{Francisco Vitor Macêdo Pereira}

Redenção, CE, Brasil.

Mestre em Filosofia pela Universidade Estadual do Ceará (2005) e doutor em Filosofia Prática pela Universidade Federal de Pernambuco (2012). Atualmente é professor efetivo da Universidade da Integração Internacional da Lusofonia Afro-Brasileira/UNILAB, professor Permanente do Mestrado Interdisciplinar em Humanidades da Universidade da Integração Internacional da Lusofonia Afro-brasileira (MIH/UNILAB), professor da Pós-graduação lato sensu (UAB/UNILAB) do Curso de Especialização em Gênero, Diversidade e Direitos Humanos

Email: vitor@unilab.edu.br

Link do Lattes: http://lattes.cnpq.br/6113552731314123

André Monteiro Moraes

Campina Grande, PB, Brasil.

Mestrando do Programa de Pós-Graduação em Serviço Social da UEPB. Especialista em Assistência Social e Políticas da Saúde (UNIFIP). Bacharel em Serviço Social pela Universidade Estadual da Paraíba (UEPB)

Email: andre.monteiro063@gmail.com

Link do Lattes: http://lattes.cnpq.br/9610990840761763

Recebimento: 25/07/2020

Aprovação: 16/09/2020

Q.Code

\section{Editores-Responsáveis}

Dr. Enéas de Araújo Arrais Neto, Universidade Federal do Ceará, UFC, Ceará, Brasil

Dr. Sebastien Pesce, Universidade de Orléans, França. 